\title{
Comparison of Clonidine and Labetalol with Regard to Haemodynamic Status, Amount of Haemorrhage, and Surgeon's Satisfaction in Rhinoplasty
}

\author{
Masood Radman ${ }^{1}$, Fatemeh Jadidi², Afsaneh Poor Jafarabadi ${ }^{3}$ \\ ${ }^{1}$ Department of Otorhinolaryngology, Refsanjan University of Medical Sciences, \\ Rafsanjan, Iran. ${ }^{2}$ Department of Anaesthesiology, Refsanjan University of Medical \\ Sciences, Rafsanjan, Iran. ${ }^{3}$ Refsanjan University of Medical Sciences, Rafsanjan, Iran.
}

ABSTRACT

\section{BACKGROUND}

Intraoperative haemorrhage is not only damaging to patients but also affects the surgeon's view of the surgical field. This study aimed to compare clonidine and labetalol with regard to haemodynamic status, amount of haemorrhage, and surgeon's satisfaction in rhinoplasty.

\section{METHODS}

Fifty patients undergoing rhinoplasty were enrolled in the study by convenience sampling method and were assigned to two groups of 25 randomly. One group received a $0.2 \mathrm{mg}$ tablet of clonidine one hour before the surgery and the other received $5-20 \mathrm{mg}$ of labetalol intravenously during the surgery. Systolic and diastolic blood pressures, and mean arterial pressure were measured before the induction of anaesthesia, after anaesthesia, and during osteotomy. The amount of blood collected by the suction machine and the weight of gases used during and after the surgery were measured. The surgeon was asked to rate his satisfaction with the surgical field as either good (clean and blood-free field), moderate (semi-clean field), or poor (blood-stained field). Data was analysed by using paired t-test, independent t-test, Chi-square test, and Fisher's exact test. A p-value of less than 0.05 was considered significant.

\section{RESULTS}

No significant difference was detected between clonidine and labetalol groups in terms of mean values of systolic blood pressure, diastolic blood pressure, arterial pressure, and heart rate $(\mathrm{p}>0.05)$. Also, there was no significant difference between these two groups in terms of the amount of bleeding and the surgeon's satisfaction with the surgical field $(p=0.062$ and $p=0.175)$.

\section{CONCLUSIONS}

Using clonidine as premedication in rhinoplasty had less intraoperative bleeding than those who received labetalol during anaesthesia, although this difference was not significant. It appears that clonidine premedication could be a good alternative to the administration of labetalol during surgery, of course, except in cases where clonidine cannot be used for any reason.

\section{KEY WORDS}

Rhinoplasty, Clonidine, Labetalol, Bleeding
Corresponding Author:

Dr. Fatemeh Jadidi,

Department of Anaesthesiology,

Faculty of Medicine,

Refsanjan University of Medical Sciences,

Rafsanjan, Iran.

E-mail: fa.jadidi.2020@gmail.com

DOI: $10.14260 /$ jemds/2020/750

How to Cite This Article:

Radman $M$, Jadidi $F$, Jafarabadi AP. Comparison of clonidine and labetalol with regard to haemodynamic status, amount of haemorrhage and surgeon's satisfaction in rhinoplasty. J Evolution Med Dent Sci 2020;9(46):3418-3421, $10.14260 / \mathrm{jemds} / 2020 / 750$

Submission 05-05-2020, Peer Review 04-08-2020, Acceptance 13-08-2020, Published 16-11-2020.

Copyright (C) 2020 JEMDS. This is an open access article distributed under Creative Commons Attribution License [Attribution 4.0 International (CC BY 4.0)] 


\section{BACKGROUND}

Rhinoplasty is the most common cosmetic surgery in many parts of the world including Iran. The purpose of this surgery and other cosmetic surgeries is to improve the patient's satisfaction with the appearance of the nose, face, and body. ${ }^{1}$ The primary objectives of rhinoplasty include decreasing or increasing the size of the nose, reshaping the tip or bridge of the nose, narrowing the nostrils, and changing the nose angle. ${ }^{2}$ Overall, the goal of cosmetic rhinoplasty is to reshape the nose to improve its appearance. ${ }^{3}$ Many surgeons and anaesthesiologists, including those specialized in rhinoplasty, have to consider and address the problem of intraoperative bleeding in the course of their work. Intraoperative bleeding not only limits the surgical field and obstructs the surgeon's vision but also causes haemodynamic changes that force the anaesthetists to take extra measures to maintain haemodynamic stability. ${ }^{4}$ An ideal blood pressure lowering agent should be easy to administer, have a short onset of action, have a short half-life, leave no toxic metabolite, and finally, have predictable dose-dependent effects, especially when operating on vital organs. ${ }^{5}$

One of the blood-pressure lowering drugs that can be used to control intraoperative bleeding is Labetalol. ${ }^{6}$ Labetalol is an antihypertensive drug that blocks both alpha- and betaadrenergic receptors and causes reduced heart rate and vasodilation simultaneously. This drug is 5 to 10 times more effective in blocking the beta-receptors than other receptors. ${ }^{7}$ Another drug that can be used to reduce intraoperative bleeding is Clonidine. ${ }^{8}$ Clonidine is an alpha-2 agonist belonging to the class of anti-adrenergic drugs with central action, which is used in the treatment of hypertension. This drug is available in the form of $0.2 \mathrm{mg}$ tablets and $0.2 \mathrm{mg} / 24$ $h$ patches. ${ }^{7}$ The sedative, anxiolytic and analgesic properties of Clonidine make it a useful premedication. ${ }^{8}$ Since intraoperative bleeding can severely reduce the surgeon's view of the area being operated on, one of the major tasks of anaesthesiologists during head and neck surgeries is to prevent this problem by controlling the bleeding. One of the main factors in the development of modern anaesthesia and surgery is to create a safe outcome for the patient. Over the past two decades, due to the increase in pathophysiological knowledge, the optimization of the disease process, the use of safer and newer drugs, continuous monitoring and preoperative control and postoperative care, mortality and morbidity have decreased significantly. ${ }^{9}$ Recognizing the physiological changes caused by surgery and anaesthesia is one of the most important medical advances in recent years. These changes directly affect the body's cardiovascular, metabolic, fluid, and electrolyte systems, increasing the risk to the patient. One of the consequences of major surgeries is metabolic stress and changes in haemodynamic parameters, which may be associated with increased mortality and morbidity. ${ }^{10}$ Because the amount of bleeding during the operation directly affects the outcome of rhinoplasty. Any action or method that reduces bleeding will be valuable. ${ }^{11}$ So far, various methods have been proposed to reduce bleeding during ear, throat, and nose surgeries. ${ }^{12}$ The aim of this study was the comparison of the use of clonidine and labetalol in the rate of rhinoplasty surgery.

\section{METHODS}

Patients undergoing rhinoplasty in Moradi Hospital (Rafsanjan, Iran, from March to September 2019) were included in the study. Based on $\alpha=0.05, \beta=10 \%, d=7, \sigma=$ $6.72^{13}$ and using the following formula, the sample size was calculated with 19 individuals per group. Subjects were selected by convenience sampling method based on the inclusion and exclusion criteria. Inclusion criteria were the age of 17 - 40 years, ASA class I (The American Society of Anesthesiologists), without history of heart disease, and absence of coagulation disorders. Exclusion criteria were sensitivity to clonidine or labetalol.

Considering the possibility of losing subjects due to withdrawal, ultimately 25 patients were assigned to each group (clonidine, labetalol).

$$
n=\frac{2(\mathrm{z} 1-\alpha / 2+\mathrm{z} 1-\beta) \sigma 2}{\mathrm{~d}^{2}}
$$

Informed consent was obtained. Subjects were and randomly assigned to two groups, $A$ and $B$, by lottery (the first name drawn was placed in group $A$, the second in group B...). Subjects in group A received a $0.2 \mathrm{mg}$ clonidine tablet with 20 $\mathrm{mL}$ of water one hour before surgery. Subjects in group B received 5-20 $\mathrm{mg}$ of labetalol intravenously during the surgery.

Data were recorded with the help of a checklist created for this purpose. Before the induction of anaesthesia, systolic and diastolic blood pressures were measured by the anaesthesiologist using the sphygmomanometer linked to the monitoring system. The mean arterial pressure and heart rate displayed by the monitoring system were also recorded in the checklist. Anaesthesia was then induced according to the protocol. Systolic blood pressure, diastolic blood pressure, and mean arterial pressure were re-measured with the same instruments 20 minutes after complete anaesthesia and start of the operation. All subjects underwent open rhinoplasty and were operated by the one surgeon using the same technique.

As with any other surgery, blood in the operation area was removed by a suction device. At the end of each operation, the assistant nurse measured the volume of the fluid collected in the tank of the suction device with a graduated beaker. Since this fluid contained not only the removed blood but also the physiological serum used for washing, the exact volume of physiological serum consumed during each surgery was recorded, and the volume of the removed blood was determined by subtracting the volume of physiological serum from the volume of the fluid. After each surgery, the surgeon, who was blinded to patients' allocation to groups, was asked to rate his satisfaction with his view of the surgical field, using the following options. ${ }^{14}$

- $\quad$ Good (clean blood-free field);

- Moderate (semi-clean field);

- $\quad$ Poor (blood-stained field).

\section{Statistical Analysis}

Data was analysed using paired t-test, independent t-test, chisquare test, and Fisher's exact test with SPSS-18. A p-value of less than 0.05 was considered significant. 


\section{Ethical Considerations}

The research design was reviewed and authorized in advance by the ethics committee of Rafsanjan University of Medical Sciences.

\section{RESULTS}

The study was performed on 50 subjects in two groups of 25, of which 22 (44\%) were male and 28 (56\%) were female. The two groups did not significantly differ in terms of gender $(\mathrm{p}=$ $0.1)$, age $(p=0.905)$ or weight $(p=0.105)$. Systolic blood pressure, diastolic blood pressure, mean arterial pressure, and heart rate were measured before anaesthesia, 20 minutes after anaesthesia, and during osteotomy. Kolmogorov-Smirnov test did not detect statistical significance in the distribution of mean arterial pressure before surgery $(p=0.651), 20$ minutes after anaesthesia ( $p=0.944)$, or during osteotomy $(p=0.871)$. Independent $t$-test showed no statistically significant difference between the mean systolic pressure of male and female subjects before anaesthesia $(\mathrm{p}=0.184), 20$ minutes after anaesthesia $(p=0.366)$ or during osteotomy $(p=0.735)$. There was also no significant difference between the mean diastolic pressure of men and women before anaesthesia $(p=$ $0.690)$ and 20 minutes after anaesthesia $(p=0.972)$, but such difference was detected for the mean diastolic pressure during osteotomy $(64.0 \pm 13.09 \mathrm{mmHg}$ for men vs. $55.73 \pm 12.54$ $\mathrm{mmHg}$ for women, $\mathrm{p}=0.048$ ). These results are presented in Table 1.

\begin{tabular}{|c|c|c|c|c|}
\hline Variable & Time & Men $(n=16)$ & $\begin{array}{c}\text { Women } \\
(n=26)\end{array}$ & $\begin{array}{c}\text { P- } \\
\text { Value }\end{array}$ \\
\hline \multirow{3}{*}{$\begin{array}{c}\text { Systolic blood } \\
\text { pressure }\end{array}$} & Before anaesthesia & $109.18 \pm 26.31$ & $117.82 \pm 15.93$ & 0.184 \\
\hline & $20 \mathrm{~min}$ after anaesthesia & $92.95 \pm 19.52$ & $97.41 \pm 13.06$ & 0.366 \\
\hline & In osteotomy & $98.64 \pm 20.10$ & $96.89 \pm 14.71$ & 0.735 \\
\hline \multirow{3}{*}{$\begin{array}{l}\text { Diastolic blood } \\
\text { pressure }\end{array}$} & Before anaesthesia & $74.87 \pm 9.25$ & $73.46 \pm 12.02$ & 0.690 \\
\hline & 20 min after anaesthesia & $57.25 \pm 8.43$ & $57.12 \pm 15.45$ & 0.972 \\
\hline & In osteotomy & $64.0 \pm 13.09$ & $55.73 \pm 12.54$ & 0.048 \\
\hline \multirow{4}{*}{$\begin{array}{l}\text { Mean arterial } \\
\text { pressure }\end{array}$} & Before anaesthesia & $90.33 \pm 11.30$ & $89.14 \pm 11.78$ & 0.748 \\
\hline & 20 min after anaesthesia & $71.67 \pm 8.74$ & $71.23 \pm 13.51$ & 0.909 \\
\hline & In osteotomy & $77.87 \pm 13.33$ & $70.05 \pm 11.70$ & 0.053 \\
\hline & Before anaesthesia & $81.41 \pm 13.71$ & $89.25 \pm 14.07$ & 0.054 \\
\hline \multirow[t]{2}{*}{ Heart rate } & 20 min after anaesthesia & $70.77 \pm 9.83$ & $76.59 \pm 8.78$ & 0.034 \\
\hline & In osteotomy & $66.59 \pm 16.75$ & $76.82 \pm 8.37$ & 0.007 \\
\hline Mean & In Systolic Blood P & sure, Diast & c Blood Pr & \\
\hline
\end{tabular}

\begin{tabular}{|c|c|c|c|c|}
\hline Variable & Time & Clonidine & Labetalol & $\begin{array}{c}\text { P- } \\
\text { Value }\end{array}$ \\
\hline \multirow{3}{*}{$\begin{array}{l}\text { Systolic blood } \\
\text { pressure }\end{array}$} & Before anaesthesia & & & 0.710 \\
\hline & 20 min after a & & 96.2 & 0.719 \\
\hline & & & & 0.654 \\
\hline \multirow{3}{*}{$\begin{array}{l}\text { Diastolic blood } \\
\text { pressure }\end{array}$} & Before anae: & 7 & 74.6 & 0.718 \\
\hline & $20 \min \mathrm{a}$ & & & 0.675 \\
\hline & In osteot & & & 0.545 \\
\hline \multirow{4}{*}{$\begin{array}{l}\text { Mean arterial } \\
\text { pressure }\end{array}$} & Before anaes & 88.3 & & 0.456 \\
\hline & $20 \mathrm{~min}$ after anaesthesia & 69.9 & & 0.394 \\
\hline & In osteotomy & 72.30 & & 0.690 \\
\hline & Before & & & 0.309 \\
\hline \multirow[t]{2}{*}{ Heart rate } & 20 min after anaesthesia & 72.58 & $75.32 \pm 8.60$ & 0.325 \\
\hline & In osteotomy & $70.64 \pm 17.49$ & $74.0 \pm 8.13$ & 0.388 \\
\hline \multicolumn{5}{|c|}{$\begin{array}{l}\text { Table 2. Mean Systolic Blood Pressure, Diastolic Blood Pressure, Mean } \\
\text { Arterial Pressure and Heart Rate in Patients Treated with Clonidine } \\
\text { and Labetalol }\end{array}$} \\
\hline
\end{tabular}

According to the independent t-test, there was no significant difference between the mean systolic blood pressure of the clonidine group and that of the labetalol group before anaesthesia $(p=0.710), 20$ minutes after anaesthesia $(\mathrm{p}=0.719)$, or during osteotomy $(\mathrm{p}=0.654)$. These groups also did not show any significant difference in terms of mean diastolic pressure before anaesthesia $(\mathrm{p}=0.718), 20$ minutes after anaesthesia ( $p=0.675)$ and during osteotomy ( $p=$ 0.545 ). The mean arterial pressure of the subjects treated with clonidine and labetalol was also compared using the independent t-test. The results of this test are presented in Table 2. These results showed no significant difference in the mean arterial pressure of the two groups before anaesthesia $(p=0.456), 20$ minutes after anaesthesia $(p=0.394)$, or during osteotomy $(p=0.690)$. Chi-square test did show a significant difference between the two groups in terms of the number of patients bleeding less than $50 \mathrm{cc}(\mathrm{p}=0.062)$, who were 12 out of 25 clonidine-receiving subjects (75.0\%), and 4 out of 25 labetalol-receiving subjects (25.0\%). Although the surgeon's satisfaction with the surgical field was higher in the clonidine group than in the labetalol group, the difference was not statically significant $(\mathrm{p}=0.175)$ (Table 3 ).

\begin{tabular}{|c|c|c|c|c|c|}
\hline Variable & Group & $\begin{array}{l}\text { Clonidine } \\
(n=25)\end{array}$ & $\begin{array}{c}\text { Labetalol } \\
(n=23)\end{array}$ & Total & $\begin{array}{c}\text { P- } \\
\text { Value }\end{array}$ \\
\hline \multirow{3}{*}{$\begin{array}{c}\text { Amount of } \\
\text { haemorrhage }\end{array}$} & Less than $50 \mathrm{cc}$ & $12(75)$ & $4(25)$ & $16(100)$ & \multirow{3}{*}{0.062} \\
\hline & $50-100 \mathrm{cc}$ & $8(36.4)$ & $14(63.6)$ & $22(100)$ & \\
\hline & $\begin{array}{l}\text { More than } 100 \\
\text { cc }\end{array}$ & $5(50)$ & $5(50)$ & $10(100)$ & \\
\hline \multirow{3}{*}{ Satisfaction } & Good & $13(65)$ & $7(35)$ & $20(100)$ & \multirow{3}{*}{0.175} \\
\hline & Moderate & $9(37.5)$ & $15(62.5)$ & $24(100)$ & \\
\hline & Poor & $3(60)$ & $2(40)$ & $5(100)$ & \\
\hline \multicolumn{6}{|c|}{$\begin{array}{l}\text { Table 3. Distribution of Bleeding and Satisfaction of } \\
\text { Surgery-Field in Clonidine and Labetalol Groups }\end{array}$} \\
\hline
\end{tabular}

\section{DISCUSSION}

This study aimed to measure and compare the extent of bleeding during rhinoplasty in patients receiving clonidine and labetalol. The results showed that the clonidine-receiving patients had a lower mean arterial pressure and heart rate before the anaesthesia and during the surgery than the labetalol-receiving patients, but this difference was not statistically significant. Also, despite the lower mean intraoperative bleeding rate (50-100 cc) and higher surgeon satisfaction with the surgical field in the clonidine-receiving group than in the labetalol-receiving group, these differences were not statistically significant.

In this respect, the results of this study are consistent with the findings of Sadri et al, who reported lower bleeding rates and, consequently, higher surgeon satisfaction with the surgical field in patients receiving clonidine. Ghazipour et al. have also reported similar results. ${ }^{15} \mathrm{~A}$ study by Tabrizi et al.

Found that the rhinoplasty patients who had received clonidine as Premedication had less bleeding than those receiving placebo. ${ }^{16}$ In a study by Ramchandani, patients taking clonidine had not only less intraoperative bleeding but also lower isoflurane, fentanyl, and metoprolol consumption. ${ }^{17}$

When comparing the effects of nitroglycerin and labetalol, Hadavi et al. found that intraoperative bleeding was lower in the nitroglycerin-receiving group but surgeon satisfaction with the surgical field was higher in the labetalol-receiving group, although none of these differences were statistically significant. ${ }^{18}$ Marchal et al. showed that using clonidine as premedication reduces bleeding during middle ear microsurgery, hyperdynamic response to tracheal intubation, 
and isoflurane, fentanyl, and urapidil consumption for controlling hypotension. ${ }^{19}$

\section{CONCLUSIONS}

Rhinoplasty patients who received clonidine as premedication had less intraoperative bleeding than those who received labetalol during anaesthesia, but this difference was not statistically significant. Clonidine premedication could be a good alternative to the administration of labetalol during surgery, except in cases where clonidine cannot be used for any other reason. Future studies are recommended to further explore this subject using larger samples and for other surgeries.

Data sharing statement provided by the authors is available with the full text of this article at jemds.com.

Financial or other competing interests: None.

Disclosure forms provided by the authors are available with the full text of this article at jemds.com.

Authors thank all OT staff, Rafsanjan University of Medical Sciences, for their assistance during the course of this study.

\section{REFERENCES}

[1] Zahiraddin AR, Khalighi Sigaroodi E. The relation between mental health and self-concept with r5hinoplasty. Pajoohandeh J 2003;8(5):9-15.

[2] Flint WP, Haughey $\mathrm{BH}$, Lund VJ, et al. Cummings otorhinolaryngology, head \& neck surgery. Canada: Sunders 2015.

[3] Ehsani A, Fakour Y, Gholamali F, et al. Prevalence of body dysmorphic disorder in patients referred to Razi hospital cosmetic clinic with complaints of cosmetic disorders. Tehran University Med J 2013;71(3):164-70.

[4] Rodrigues RR, Carmona MJ, Junior JOCA. Bleeding and damage control surgery. Curr Opin Anaesthesiol 2016;29(2):229-33.

[5] Degoute CS. Controlled hypotension: a guide to drug choice. Drugs 2007;67(7):1053-76.

[6] Webster LM, Myers JE, Nelson-Piercy C, et al. Labetalol versus nifedipine as antihypertensive treatment for chronic hypertension in pregnancy: a randomized controlled trial. Hypertension 2017;70(5):915-22.

[7] Trevor A, Katzung B, Masters S, et al. Katzung \& Trevor's pharmacology examination and board review. $10^{\text {th }}$ edn. McGraw-Hill Education 2012.
[8] Sadri B, Nadri S, Poosti B, et al. Clonidine decreased intraoperative bleeding in rhinoplasty. Scientific Magazine Yafte 2007;9(2):25-30.

[9] Gropper MA, Eriksson LI, Fleisher LA. Miller's anaesthesia. $9^{\text {th }}$ edn. Elsevier 2019.

[10] Tewari N, Awad S, Duška F, et al. Postoperative inflammation and insulin resistance in relation to body composition, adiposity and carbohydrate treatment: a randomised controlled study. Clin Nutr 2019;38(1):20412.

[11] Ghodraty M, Khatibi A, Rokhtabnak F, et al. Comparing labetalol and nitroglycerine on inducing controlled hypotension and intraoperative blood loss in rhinoplasty: a single-blinded clinical trial. Anaesth Pain Med 2017;7(5):e13677.

[12] Berenjian S, Hassani V, Farhadi M, et al. Comparing the effect of Tranexamic acid and Dexmedetomidine on bleeding during Rhinoplasty. Anaesthesiology and Pain 2016;6(3):36-43.

[13] Bhuava A, Bhuava AN, Kharde V, et al. Effect of oral clonidine premedication on perioperative haemodynamic response- a randomized double blind placebo controlled study. Indian J Clin Anaesth 2016;3(1):4-11.

[14] Jadidi F, Karami M. Investigating the relationship between anaesthesia depth monitoring and field transparency in limited surgery fields (ear, noise, and sinus) in moradi hospital of rafsanjan city in 2016: a short report. J Rafsanjan University of Med Sci 2017;15(12):1173-80.

[15] Ghazipour A, Ahmadi K, Sarafraz M, et al. Can clonidine as a pre-anaesthetic drug decrease bleeding during rhinoplasty surgery? Indian J Otolaryngol Head Neck Surg 2013;65(Suppl 2):301-3.

[16] Tabrizi R, Eftekharian H, Pourdanaesh F, et al. Does oral clonidine premedication decrease bleeding during open rhinoplasty? J Craniofac Surg 2014;25(3):1101-3.

[17] Ramchandani S, Lakra AM, Shah PJ, et al. Effect of intravenous clonidine premedication for the bloodless surgical field in patients undergoing middle ear or nasal surgery: a comparison of three different doses. Anaesth Essays Res 2015;9(3):397-400.

[18] Hadavi MR, Zarei Y, Tarogh S. Comparison of effects of labetalol and nitroglycerine on intraoperative blood loss and surgical field quality in rhinoplasty surgery. World J Plast Surg 2015;4(1):60-5.

[19] Marchal JM, Gomez-Luque A, Martos-Crespo F, et al. Clonidine decreases intraoperative bleeding in middle ear microsurgery. Acta Anaesthesiol Scand 2001;45(5):62733. 